\title{
Surface-modified Colloid CdTe/CdS Quantum Dots by a Biocompatible Thiazolidine Derivative as Promising Platform for Immobilization of Glucose Oxidase: Application to Fluorescence Sensing of Glucose
}

Rahman Hallaj ( $\square$ rhallaj@uok.ac.ir)

University of Kurdistan https://orcid.org/0000-0002-7952-7248

Zahra Hosseinchi

University of Kurdistan

Research Article

Keywords: Fluorescence, CdTe/CdS Quantum Dots, Glucose Oxidase

Posted Date: July 30th, 2021

DOI: https://doi.org/10.21203/rs.3.rs-661235/v1

License: (c) (1) This work is licensed under a Creative Commons Attribution 4.0 International License.

Read Full License 


\section{Abstract}

This work focuses on the synthesis of novel modified core-shell CdTe/CdS quantum dots (QDs) and develops as a fluorescence sensor for glucose determination. The (E)-2,2'-(4,4'-dioxo-2,2'-dithioxo-2 H,2' $\mathrm{H}$ [5,5'-bithiazolylidene]-3,3'(4H,4'H)-diyl)bis(3- mercaptopropanoic acid) (DTM) as a new derivative of thiazolidine was synthesized and characterized and used to surface-modification of CdTe/CdS QDs. DTM-capped CdTe/CdS QDs used to immobilization of glucose oxidase (GOD). The intensity fluorescence emission of the CdSe/CdS-DTM/GOD is highly sensitive to the concentration of $\mathrm{H}_{2} \mathrm{O}_{2}$ as a byproduct of the catalytic oxidation of glucose. The experimental results showed that the quenched fluorescence was proportional to the glucose concentration within the range of $10 \mathrm{nM}-0.32 \mu \mathrm{M}$ under optimized experimental conditions. The limit of detection of this system was found to be $4.3 \mathrm{nM}$. Compared with most of the existing methods, this newly developed system possesses many advantages, including simplicity, low cost, and good sensitivity.

\section{Introduction}

Enzymes, as a natural, specific and selective catalyst, plays important role in the acceleration of biological transformation in living cells. Poor structural stability and inherent drawbacks limited the extracellular applications of enzymes [1]. To overcome these challenges, localization and immobilization of enzymes have been proposed. Furthermore, compared with free enzymes, immobilized enzymes, enhanced the resistance and stability [2], selectivity, specificity [3], and possibly prevent inhibition and denaturing [4]. Nanostructured materials are an excellent candidate for loading various biological molecules and enzymes due to their large area and biocompatibility. Until now numerous nanomaterials have been applied to immobilization of enzymes and biomolecules. Carbon nanotube [5], Zinc oxide [6], nickel and cobalt oxide [7,8], gold-coated polymeric nanofiber [9], metal-organic formwork [10], and Covalent organic frameworks [11], are some examples of these nanomaterials. Until now several strategies used to anchoring biomolecules and enzymes on the surface of nanostructures, mainly including chemical bonding and physical attachment. Due to the strong bond between the surface and enzyme, lower stability, and leakage of the enzyme, the covalent attachment has received more attention. Therefore, functionalization and surface modification with activating agents are of considerable interest [12]. Due to their unique size-dependent optical and electronic properties, nanocrystalline semiconductors, so-called quantum dots (QDs), have attracted a lot of attention in the field of chemical and biological applications, $[13,14]$. Attachment of enzymes onto the surface of QDs reduces protein unfolding and turmoil and improves enzyme stability [15]. Surface modification of QDs by enzymes is a successful strategy for the design and construction of sensors and biosensors. Recently, several modified QDs were used to immobilization of glucose oxidase and finally used as glucose biosensors. For example, Zhou and coworkers used CdTe/ZnTe/ZnS QDs modified by phenylboronic acid (PBA) for intracellular glucose probing [16]. Guin and et al. used 3-mercaptopropanoic acid (MPA) capped CdTe QDs functionalized by glucose oxidase [17]. Yan and co-workers reported the conjugation of glucose oxidase (GOD) onto Mndoped ZnS quantum dots (QDs) [18]. Choi et al. applied GOD immobilized on the TGA-capped CdSe QDs 
for the detection of glucose concentrations in real human blood samples [19]. In this work, a new derivative of thiazolidine, named MDT, was synthesized and characterized, and used to surfacemodification of CdTe/CdS QDs. The MDT capped CdTe/CdS QDs applied as a new host molecule to the binding of Glucose oxidase. The results show that the fluorescence emission of CdTe / CdS-DTM / GOD is quenched by $\mathrm{H} 2 \mathrm{O} 2$ which can be produced during enzymatic oxidation of glucose. Monitoring the produced $\mathrm{H} 2 \mathrm{O} 2$ during the enzymatic oxidation of glucose is a common method for glucose determination [20]. Therefore, the CdTe/CdS-DTM/GOD use as the fluorescence probe for the determination of glucose concentration. This system possesses many advantages, low cost, including simplicity, high selectivity, and good sensitivity. Glucose, as the major energy source of cells, plays an essential role in organisms [21]. Therefore, the determination of glucose concentration is very crucial in the field of biomedicine and food processes [22]. Various methods such as fluorescence, electrochemistry have been reported for the detection of glucose based on glucose oxidase (GOD) catalyzed oxidation mechanism $[23,24]$.

\section{Experimental Section}

\subsection{Chemicals Reagent and apparatus}

Glucose oxidase, glucose, Tellurium dioxide, L-cysteine, $\mathrm{CdCl}_{2} \cdot 2.5 \mathrm{H}_{2} \mathrm{O}$, and Sodium borohydride $\left(\mathrm{NaBH}_{4}\right)$ were obtained from Sigma -Aldrich. Thioacetamide, Carbon disulfide, dimethyl acetylenedicarboxylate, Thioglycolic acid (TGA, 98\%), other chemicals were of the highest purity available and used without purification. All fluorescence spectra were recorded by a Cary Eclipse fluorescence spectrophotometer (Varian, Inc.) equipped with a xenon discharge lamp as the source lamp and a quartz cell. The UV-vis spectra were measured on the Varian Cary UV-vis spectrometer.

\subsection{Synthesis of dioxo-dithio bithiazolidine ligand}

The synthesis of DTM was based on the reported method [25]. Briefly, L-cysteine (4 mmol) was added dropwise to a stirred mixture solution of carbon disulfide $(4.8 \mathrm{mmol})$ and dimethyl acetylene dicarboxylate (DMAD) (2 mmol). After completion of the reaction, the solution color changed from clear to dark orange. Moreover, the addition of ethanol to the reaction mixture formed the product as orange crystals. Finally, the resulting solid was filtered and dried. The structural formula of synthesis of DTM was depicted in fig.1.

\subsection{Synthesis of CdTe/CdS core/shell QDs}

The synthesis of CdTe/CdS core/shell QDs was performed as for reported methods, with some variations [26,27]. Briefly, $0.456 \mathrm{~g} \mathrm{CdCl}_{2} .2 .5 \mathrm{H}_{2} \mathrm{O}$ and $300 \mu \mathrm{L}$ of TGA were added to the $100 \mathrm{~mL}$ of deionized water under stirring. The $\mathrm{pH}$ of the solution was adjusted to 11.3 by $1.0 \mathrm{M} \mathrm{NaOH}$ under $\mathrm{N}_{2}$. Then $0.0318 \mathrm{~g}$ of powder $\mathrm{TeO}_{2}$ was added to the solution of $0.1 \mathrm{~g} \mathrm{NaBH}_{4}$ in $5 \mathrm{~mL}$ deionized water under stirring in a small flask. Clear yellow CdTe QDs was prepared by injecting the freshly prepared purple $\mathrm{NaHTe}$ solution to the above $\mathrm{Cd}$ mixture under vigorous stirring. Then, the solution was refluxed at $90^{\circ} \mathrm{C}$ 
for $50 \mathrm{~min}$ and the small CdTe cluster solution was obtained. In the following, $3.12 \mathrm{~mL}$ thioacetamide was added to as-prepared CdTe QDs under $\mathrm{N}_{2}$ bubbling and stirring constantly. The CdTe@CdS QDs were synthesized by further aging small CdTe cluster solution at $70-80^{\circ} \mathrm{C}$ for $30 \mathrm{~min}$.

\subsection{Preparation of DTM capped CdTe/CdS core/shell QDs}

$0.005 \mathrm{~g}$ of DTM was weighed accurately and dispersed in $5 \mathrm{~mL}$ of phosphate buffer $(0.1 \mathrm{M}, \mathrm{pH}=7.4)$ for $30 \mathrm{~min}$. Then, $1.5 \mathrm{~mL}$ of CdTe@CdS functionalized with $1.5 \mathrm{~mL}$ of ligands after $15 \mathrm{~min}$. The modified QDs showed their best intensity of fluorescence. (Scheme 1 ).

\subsection{Conjugation of GOD on DTM capped QDs (DTM-CdTe/ CdS- GOD QDs)}

The CdTe/CdS-DTM conjugated with GOD using the EDC/NHS via the formation of an amide linkage between the carboxyl group of DTM and the primary amine group of the GOD. At first, the $1.5 \mathrm{ml}$ of the phosphate buffer solution $(0.1 \mathrm{M}, \mathrm{pH}=7.4)$ containing $0.26 \mathrm{mmol}$ EDC and $0.05 \mathrm{mmol} \mathrm{NHS}$ was added to $2 \mathrm{~mL}(5 \mathrm{mg} / \mathrm{mL})$ of DTM capped QDs and stirred at room temperature for $30 \mathrm{~min}$. Then, $2 \mathrm{mg}$ of a GOD solution was added to the activated QDs and kept at $4{ }^{\circ} \mathrm{C}$ for $6 \mathrm{~h}$. The sediment of CdTe/ CdS- GOD QDs was formed by the addition of acetone. The excess amount of reagent washed with water and the CdTe/ CdS- GOD QDs separated with centrifugation at $8000 \mathrm{rpm}$ subsequently. The predicated QDs was kept under dark at $4^{\circ} \mathrm{C}$ and suspended in a phosphate buffer solution before use (Scheme 2).

\section{Results And Discussion}

\subsection{Characterization of CdTe/CdS-DTM QDs and CdTe/ CdS-DTM-GOD QDs}

TEM and AFM images were used for the characterization of prepared QDs. The obtained TEM and AFM images show that the prepared CdTe/CdS QDs were monodisperse and uniform structure with an average size of $4 \mathrm{~nm}$ (Fig.3A, B). The EDS spectrum in Fig.3C reveals the characteristic peaks which corresponded to the presence of $\mathrm{Cd}, \mathrm{Te}$, and $\mathrm{S}$ in the CdTe/CdS QDs. Successful conjunction of GOD to CdTe/CdS QDs was evaluated by UV-Vis and FT-IR spectroscopy. Fig. 4A depicted the UV-vis absorption spectrum for free GOD (curve a) and CdTe/CdS-GOD (curve b). As shown a well-known adsorption peak next to $450 \mathrm{~nm}$ is shown for free glucose oxidase solution and the same absorption peak showed for CdTe/CdS-GOD, indicating the successful conjugation. Similarly, the FT-IR spectroscopy was used to monitor the DTM attachment to CdTe/CdS QDs. Fig 4B, Shows FT-IR spectra for DTM (curve a) and DTM capped $\mathrm{CdTe} / \mathrm{CdS}$ (curve b). Comparing the two spectra implied to successful attachment of DTM. The most important evidence is the absence of S-H stretching vibration broad peak at $2565 \mathrm{~cm}^{-1}$ which disappears in FT-spectra for DTM capped CdTe/CdS QDs. Also, the well-defined peak at 722 and 1223 $\mathrm{cm}^{-1}$ characterizes $\mathrm{C}=\mathrm{S}$ and $\mathrm{C}-\mathrm{S}$ implies to successful attachment of DTM to CdTe/CdS QDs.

\subsection{Effect of $\mathrm{H}_{2} \mathrm{O}_{2}$ on fluorescence of DTM-CdTe/CdS-GOD QDs}


The glucose detection is based on the quenching effect of $\mathrm{H}_{2} \mathrm{O}_{2}$ on the fluorescence of DTM-CdTe/CdSGOD QDs. As can be seen (Fig. 5) the fluorescence intensity of CdTe/CdS-DTM-GOD QDs was quenched periodically due to the addition of $\mathrm{H}_{2} \mathrm{O}_{2}$. The effect of $\mathrm{H}_{2} \mathrm{O}_{2}$ is attributed to the two factors. The thiol groups in the structure of DTM and TGA on the surface of QDs oxidized by enzymatically produced hydrogen peroxide to form an organic disulfide (RS-SR). Hence, some thiol molecules are separated from the surface of the QDs and quenched the fluorescence intensity [28, 29]. The second proposed mechanism is the electron-transfer reaction between QDs and hydrogen peroxide. The electron-transfer reaction occurs when the hydrogen peroxide is reduced to $\mathrm{O}_{2}$, on the surface of $\mathrm{CdTe} / \mathrm{CdS}$ quantum dots, the electron accepted by created hole on the $\mathrm{CdTe} / \mathrm{CdS}$ and quenched the fluorescence of $\mathrm{CdTe} / \mathrm{CdS}$ [3032]. Based on the mentioned principles and due to the sensitivity of CdTe/CdS-DTM-GOD toward $\mathrm{H}_{2} \mathrm{O}_{2}$ the sensitive glucose sensor could be designed.

\subsection{Detection of glucose with DTM-CdTe/CdS- GOD QDs as fluorescence probes}

GOD catalyzes the oxidation of glucose to gluconic acid and release $\mathrm{H}_{2} \mathrm{O}_{2}$ in the presence of oxygen. Based on what was discussed, glucose can be detected by the effect of the enzymatic release of $\mathrm{H}_{2} \mathrm{O}_{2}$ on fluorescence QDs. Fig. 6, shows the quenching effects of glucose on the assay system. As depicted, the fluorescence intensity of DTM-CdTe/CdS-GOD was clearly to be quenched due to the adding diverse amount of glucose. Since $\mathrm{pH}$ plays a significant role in the enzymatic reactions, the relation between the $\mathrm{pH}$ of the solution and fluorescence intensity of DTM-CdTe/CdS-GOD QDs was studied at different $\mathrm{pH}$ (5.0-12.0). The maximum quenching effect showed at about $\mathrm{pH}=7.4$. Under optimal conditions, changes of fluorescence of the sensor investigated in the presence of different concentrations of glucose. As shown in Fig. 6, fluorescence intensity decreased linearly, due to the increased glucose concentration. The results indicate a good linear relationship between $\mathrm{I}_{0^{-1}}-1 / \mathrm{I}_{0}$ and glucose concentration in the range $0.32 \times 10^{-}$ $6-10 \times 10^{-9} \mathrm{M}$. The calculated detection limit was $4.26 \mathrm{nM}(3 \mathrm{~S} / \mathrm{m})$ and the limit of quantification was measured as $12.8 \mathrm{nM}$. The limit of detection of this system was much lower than other $\mathrm{H}_{2} \mathrm{O}_{2}$ and acidic change quenched fluorescence intensity of QD-based methods for glucose detection. Table. 1 shows a comparison of the glucose detection methods based on quenching of QDs fluorescence intensity. The comparison of analytical parameters with the other works indicates that the proposed enzyme-modified QDs is a reliable substrate for glucose detection.

\section{Real sample}

Finally, the application of our proposed sensing system in the detection and determination of glucose in human blood serum samples has been investigated. Evidently, the results represented that this QD-based glucose detection method is close to the values provided by the local laboratory. According to the calibration curve, the concentration of glucose in serum after applying the dilution effect was $3.23 \mathrm{mM}$ (Fig. 7).

\section{Conclusion}


In this work, the DTM was synthesized and used as a suitable multifunctional substrate for enzyme immobilization. The results show that the structure and activity of glucose oxidase were preserved after immobilization on the surface DTM-CdTe/CdS QDs. Based on the designed enzyme-modified QDs a sensitive fluorescence sensor was developed for the detection of glucose. The prepared probe was extremely sensitive to $\mathrm{H}_{2} \mathrm{O}_{2}$, which was released enzymatically during the oxidation of glucose. The constructed sensor indicates relatively good sensitivity and high selectivity. A good linear relationship between $\mathrm{I}_{0}-1 / \mathrm{I}_{0}$ and glucose concentration was obtained in the range $0.32 \times 10^{-6}-10 \times 10^{-9} \mathrm{M}$ also, the detection limit was measured as $4.26 \mathrm{nM}$. According to these advantages, we observed that the proposed sensor will be a promising tool for clinical analysis of glucose and even other fields.

\section{Declarations}

Funding (information that explains whether and by whom the research was supported)

The authors declare that, this research received no specific grant from any funding agency.

Conflicts of interest/Competing interests (include appropriate disclosures)

The authors declare that they have no known competing financial interests or personal relationships that could have appeared to influence the work reported in this paper.

Availability of data and material (data transparency)

The data that support the findings of this study are openly available in the public domain.

\section{Code availability (software application or custom code)}

There was not use any new software application or custom code in our report.

\section{Authors' contributions}

All authors contributed to the study conception design and data acquisition.

Additional declarations for articles in life science journals that report the results of studies involving humans and/or animals

This article does not contain any studies involving human participants

Ethics approval (include appropriate approvals or waivers)

All studies were conducted in accordance with principles for human experimentation

\section{Acknowledgments}


The financial support of the Iranian Nanotechnology Initiative and Research Office of the University of Kurdistan are gratefully acknowledged.

\section{References}

[1] N. Ye, X. Kou, J. Shen, S. Huang, G. Chen, G. Ouyang (2020) Chem. BioChem. 18, 2585, 2590.

[2] X. L. Wu, M. Hou, J. Ge (2015) Catal. Sci. Technol. 5, 5077-5085.

[3 ] C. Mateo, J.M. Palomo, G. Fernandez-Lorente, J.M. Guisan, R. Fernandez-Lafuente, (2007) Enzym. Microb. Technol. 40, 1451-1463.

[4] R.C. Rodrigues, C. Ortiz, A. Berenguer-Murcia, R. Torres, R. Fernández-Lafuente (2013) Chem. Soc. Rev. 42, 6290-6307.

[5] A. Salimi, R. G Compton, R. Hallaj (2004) Anal. Biochem. 333, 49-56. ht

[6] F. Miao, X. Lu, B. Tao, R. Li, P. K. Chu (2016) Microelectron. Eng. 159, 153-158.

[7] A Salimi, E Sharifi, A Noorbakhsh, S Soltanian (2007) Biosens. Bioelectron. 22, 3146-3153.

[8] A. Salimi, R. Hallaj, S.Soltanian (2009) Electroanalysis 21, 2693-2700.

[9] A. Aldea, R. Jose, B. Leote, E. Matei, A. Evanghelidis, I. Enculescu, V.C. Diculescu, (2021) Microchem. J. 165101068.

[10] H. Xia, N. Li, X. Zhong, Y. Jiang, Metal-Organic Frameworks (2020) Front Bioeng Biotechnol. 8, 695.

[11] J.S.Gan, A, R. Bagheri, N. Aramesh, I.Gul, M.Franco, Y. Q. Almulaiky. M. Bila, (2021) Int. J. Biol. Macromol. 167, 502-515.

[12] P. Zucca, E. Sanjust (2014) Molecules 19, 14139-14194.

[13] A. M. Smith and S. Nie (2010) Acc. Chem. Res43, 190-200.

[14] X. Wang, M. J. Ruedas-Rama, and E. A. H. Hall (2007) Anal. Lett.40, 1497-1520.

[15] L. Cui, X. P. He, and G. R. Chen (2015) RSC Adv.5, 26644-26653.

[16] W. Wu, T. Zhou, A. Berliner, P. Banerjee, and S. Zhou(2010) Angew. Chemie Int. Ed., 49, 6554-6558.

[17] P. Singh, A. a. Prabhune, S. B. Ogale, and D. Guin (2013) J. Mater. Chem. B, 47, 6538-6543.

[18] P. Wu, Y. He, H.-F. Wang, and X.-P. Yan (2010) Anal. Chem. 82, 1427-1433.

[19] E.Y. Jung, J.H. Ye, S.H. Jung, and S.H. Choi (2016) J. Nanomater. 2016, 1-9, 
[20] Y. C. Shiang, C. C. Huang, and H. T. Chang (2009) Chem. Commun. 23, 3437-3439.

[21] H.Qadri, M.F.Qureshi, M. A. Mir, A.H.Shah (2021) Microbiol. Res. 247, 126725.

[22] P. k. Crane, R. Walker, R. A. Hubbard, G. Li, D. M. Nathan, H. Zheng, S. Haneuse, S. Craft, T. J.Montine, S. E. Kahn, W. McCormick, S. M. McCurry, J. D. Bowen, E. B. Larson (2013) N Engl J. Med. 369, 540-548.

[23] L. Chen, E. Hwang, and J. Zhang (2018) Sensors (Switzerland)18, 1-21.

[24] R. Batool, A. Rhouati, M. H. Nawaz, A. Hayat, and J. L. Marty (2019) Biosensors 9, 1-19.

[25] S. A. Farough Nasiri, Amin Zolali (2012) J. Heterocycl. Chem.49,1458-1461.

[26] H. Peng, L. Zhang, C. Soeller, and J. Travas-Sejdic (2007) J. Lumin.127, 721-726.

[27] S. Z. Rahman Hallaj, Zahra Hosseinchi, Bahareh Babamiri (2019) Spectrochim. Acta Part A Mol. Biomol. Spectrosc.216, 418-423.

[28] M. Hu, J. Tian, H.-T. Lu, L.-X. Weng, and L.-H. Wang (2010) Talanta82, 997-1002.

[29] Y.-C. Shiang, C.-C. Huang, and H.-T. Chang (2009) Chem. Commun.23, 3437-3439.

[30] L. Cao, J. Ye, L. Tong, and B. Tang (2008) Chem. -A Eur. J.14, 9633-9640.

[31] I. L. Medintz, A. R. Clapp, H. Mattoussi, E. R. Goldman, B. Fisher, J. M. Mauro, S (2003) Nature Materials 2, 630-638.

[32] H.Peng, L. Zhang, T. H. M. Kjällman, C. Soeller (2007) J. Am. Chem. Soc. 129, 3048-3049.

[33] L. Wu, Z. zhong Lin, H. ping Zhong, X. mei Chen, and Z. yong Huang (2017) S ens. Actuat. B Chem. $239,69-75$.

[34] Y. Tang, Q. Yang, T. Wu, L. Liu, Y. Ding, and B. Yu (2014) Langmuir30, 6324-6330,.

[35] L. Ding, B. Zhang, C. Xu, J. Huang, and Z. Xia(2016) Anal. Methods8, 2967-2970.

[36] G. M. Durán, T. E. Benavidez, Á. Ríos, and C. D. García, (2016) Microchim. Acta183, 611-616.

\section{Tables}

Table. 1. Comparison of QDs fluorescence quenching-based optical detection methods for glucose. 


Sensor $\quad \begin{aligned} & \text { Detection of Detection Range Reference } \\ & \text { Limit }\end{aligned}$
CdTe quantum dots
$0.059(\mu \mathrm{M})$
$0.1-20 \mu \mathrm{M}$

coated with molecularly imprinted

Polymer

\begin{tabular}{llll}
\hline CdSe QDs assembled on AgNPs & $1.86(\mathrm{mM})$ & $2-52 \mathrm{mM}$ & {$[34]$} \\
\hline CdTe/CdS QDs-GOx Complex & $0.1(\mathrm{mM})$ & $0.1-7 \mathrm{mM}$ & {$[35]$} \\
\hline CdSe/ZnS Modified Paper-based Optical & $5\left(\mu \mathrm{g} \cdot \mathrm{dL}^{-1}\right)$ & $5-200 \mathrm{mg} \cdot \mathrm{dL}^{-1}$ & {$[36]$} \\
\hline DTM functionalized CdTe/CdS QDs & $4.26 \mathrm{nM}$ & $\begin{array}{l}0.32 \mu \mathrm{M}-10 \\
\mathrm{nM}\end{array}$ & $\begin{array}{l}\text { Current } \\
\text { method }\end{array}$
\end{tabular}

Figures

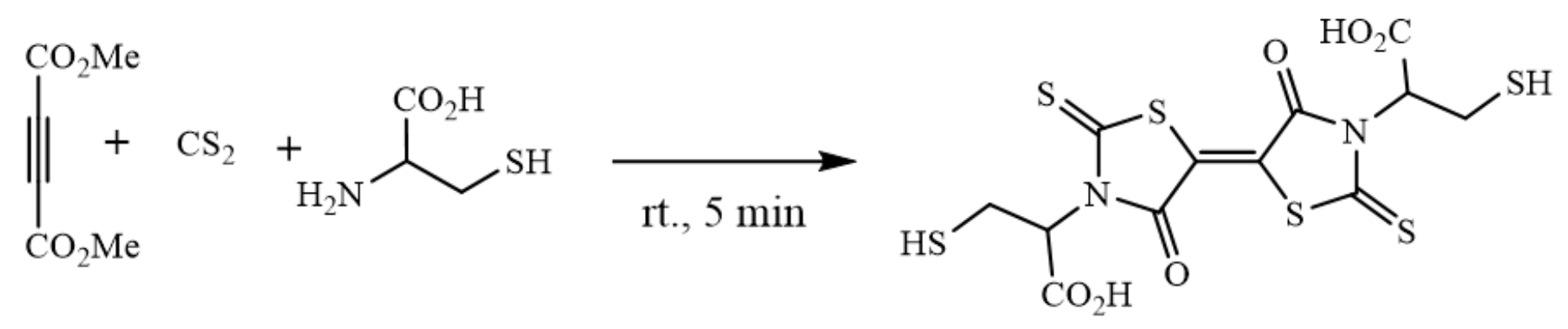

\section{Figure 1}

The structural formula for the production of DTM. 


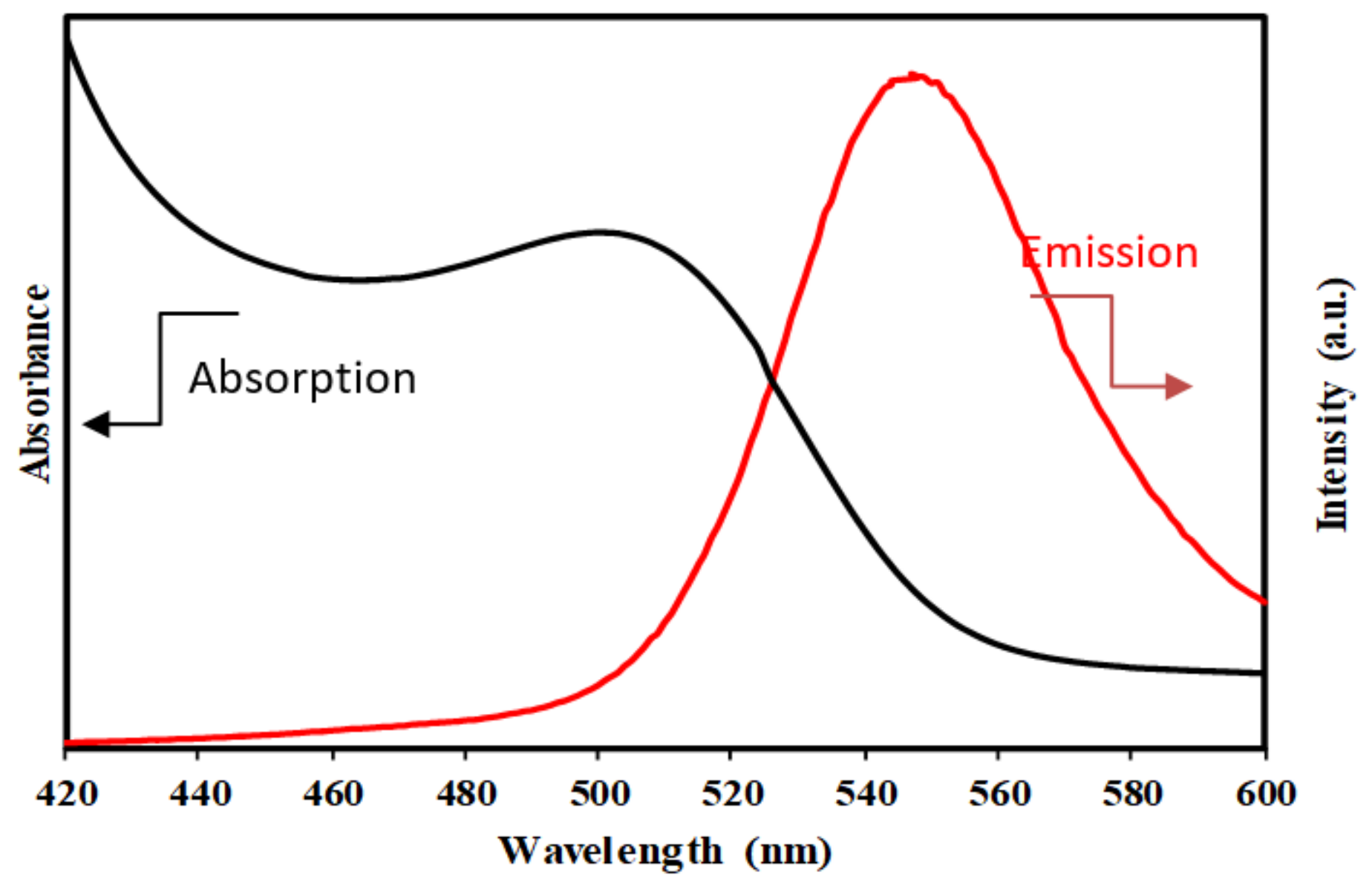

Figure 2

a) the UV-Vis absorption of the prepared CdTe/CdS QDs and b) the recorded photoluminescence spectra of the prepared CdTe/CdS QDs with the excitation wavelength of $296 \mathrm{~nm}$. 

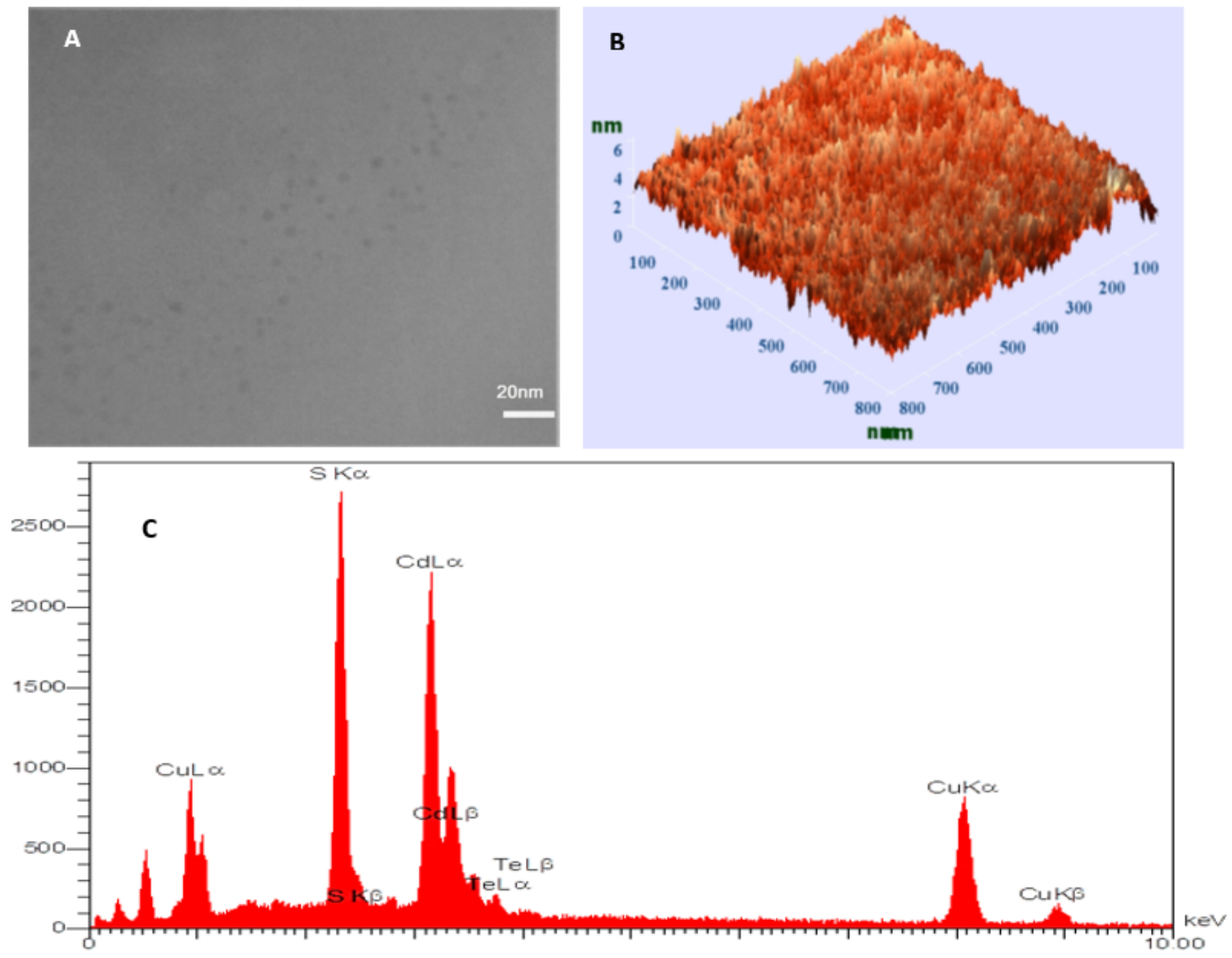

Figure 3

A) TEM spectra of as-prepared CdTe/CdS Qds, B) AFM image (Three- dimensional image) of as-prepared of CdTe/CdS QDs) and C) EDS spectra of as-prepared CdTe/CdS Qds. 

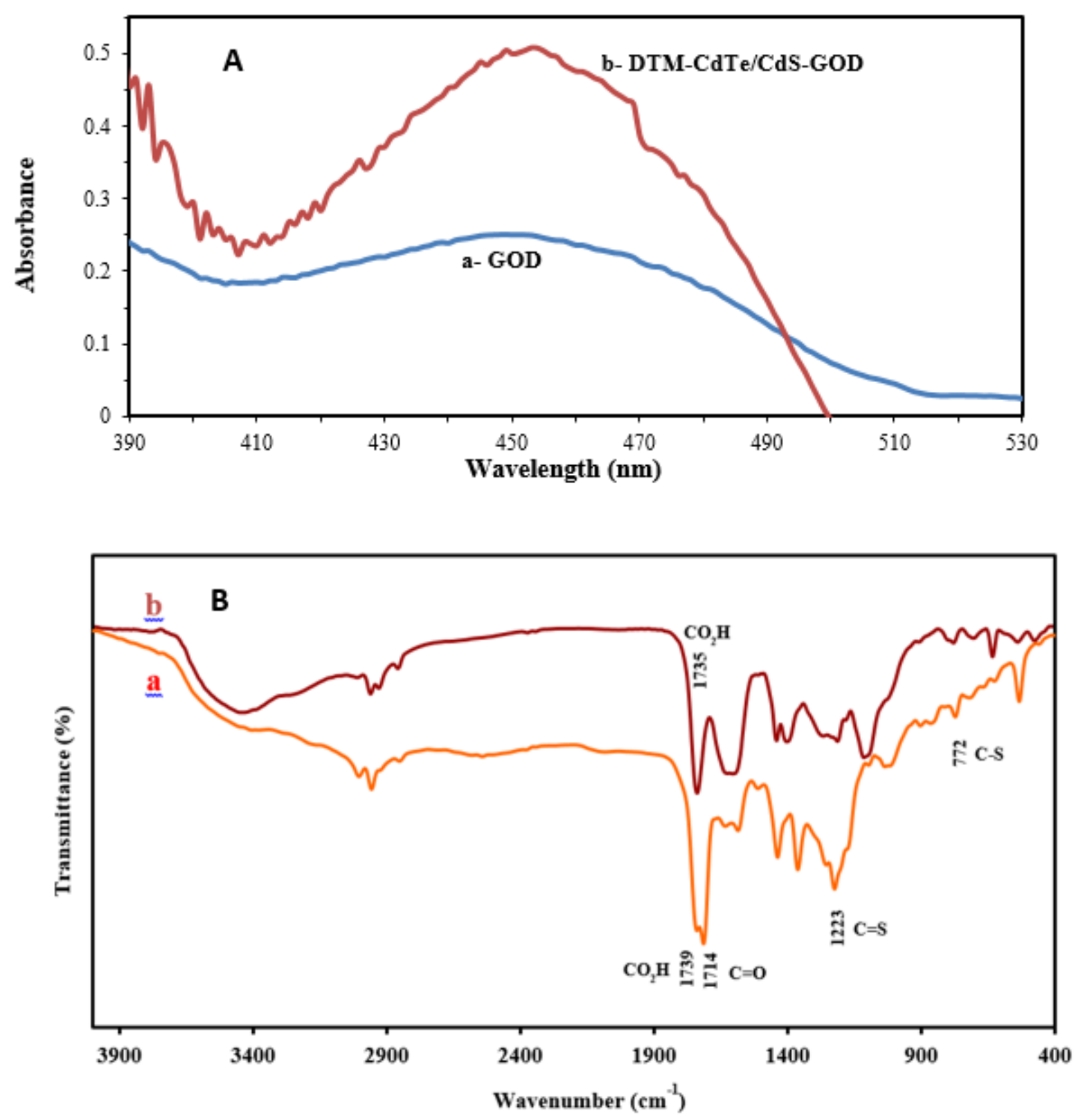

Figure 4

A)The UV-Vis spectra of a) free GOD and b) DTM-CdTe/CdS-GOD, B) FTIR spectra of (a) DTM and (b) DTM-CdTe/CdS. 


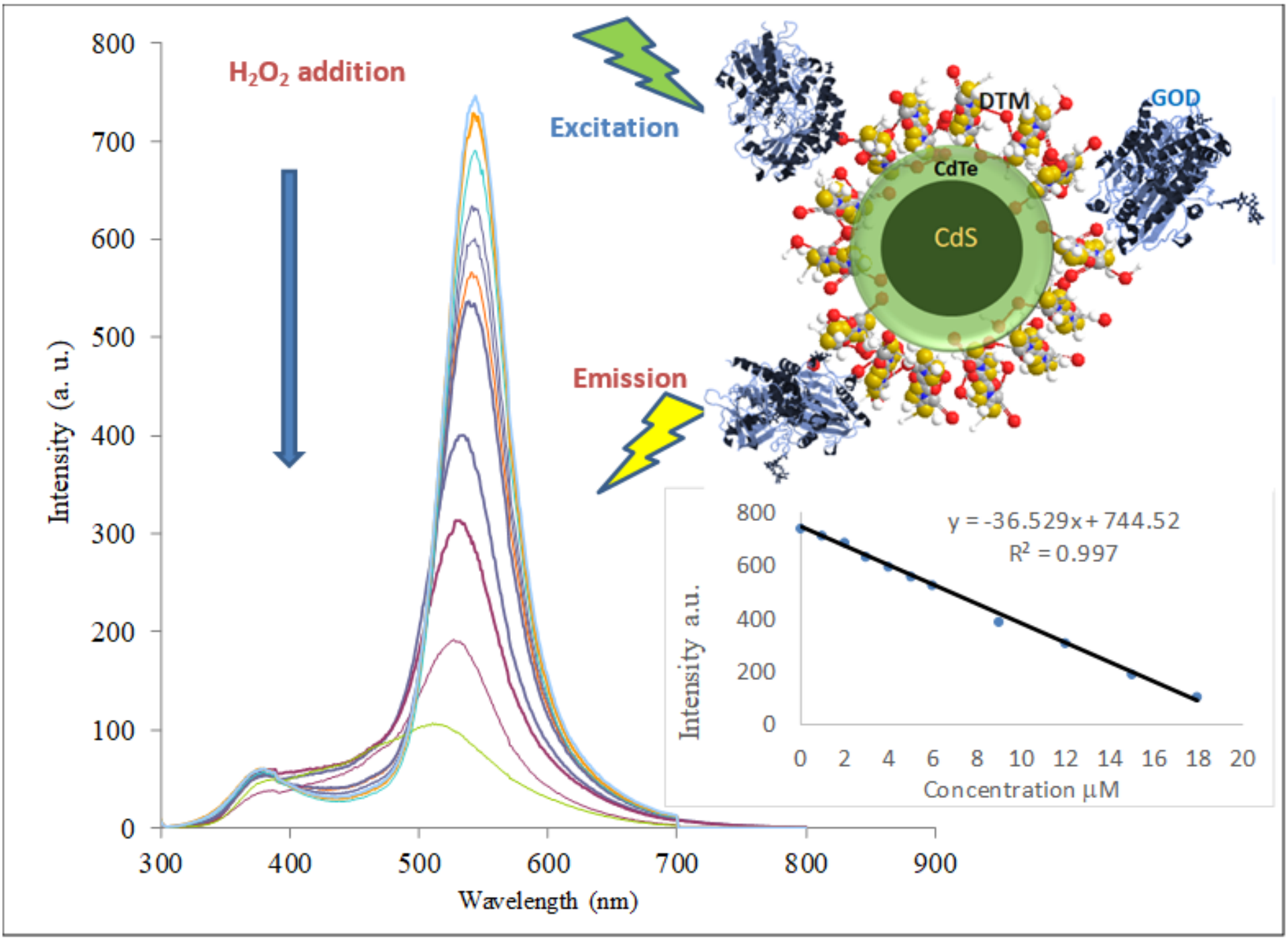

Figure 5

Fluorescence emission spectra of QDs in the presence of increasing concentrations of $\mathrm{H} 2 \mathrm{O} 2(10-90 \mu \mathrm{M})$ 


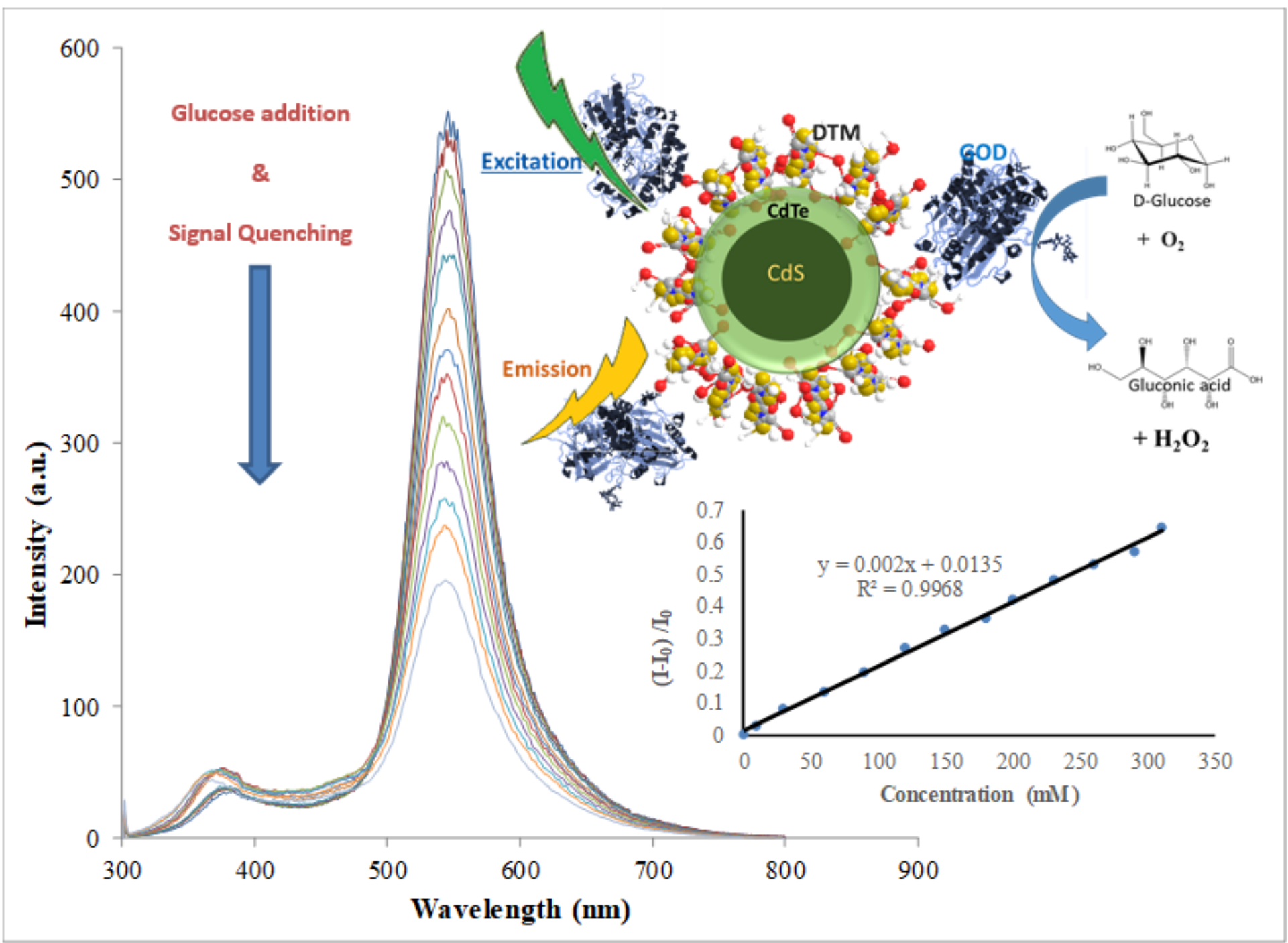

Figure 6

Fluorescence emission spectra of the glucose oxidase-quantum dot (GOD-QD) system in the presence of increasing concentrations of glucose $(10 \times 10-9-0.32 \times 10-6 \mathrm{M})$. Linear plots of relative fluorescence intensity $(I 0-1 / 10)$ vs. the concentration of glucose. 


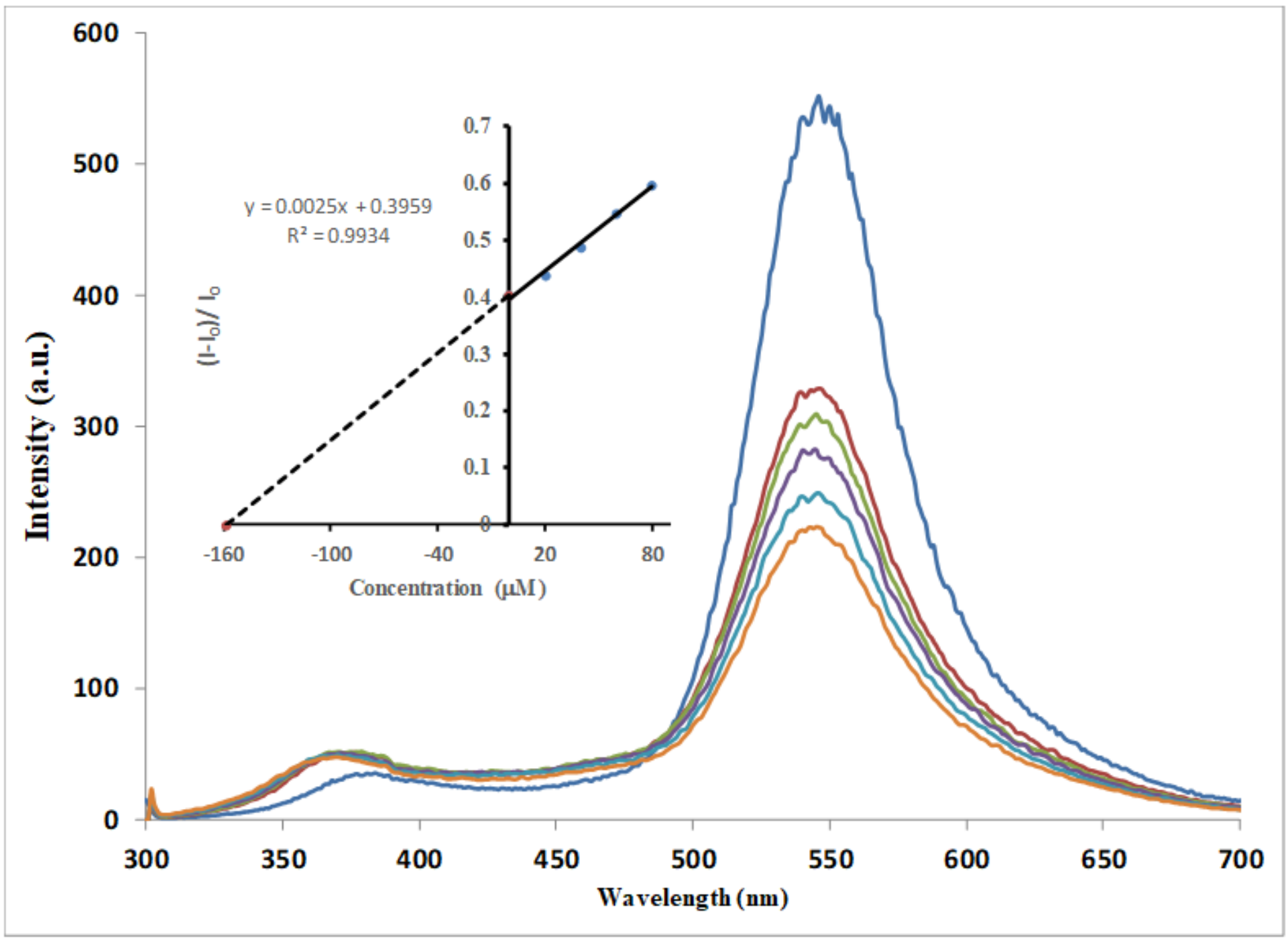

Figure 7

Fluorescence emission spectra and linear plots of relative fluorescence intensity $(10-1 / 10)$ vs. the concentration of glucose in the real sample.

\section{Supplementary Files}

This is a list of supplementary files associated with this preprint. Click to download.

- Graphicalabstract.png

- SCHEME1.png

- SCHEME2.png 